\title{
Overall-Mouth Disinfection by Photodynamic Therapy Using Curcumin
}

\author{
Natália Costa Araújo, M.D., Carla Raquel Fontana, Ph.D.,,3 \\ Marleny Elizabeth Martinez Gerbi, Ph.D. and Vanderlei Salvador Bagnato, Ph.D. ${ }^{3}$
}

\begin{abstract}
Background data: Photodynamic therapy is a technique that involves the activation of photosensitizers by light in the presence of tissue oxygen, resulting in the production of reactive radicals capable of inducing cell death. Objective: The present study assessed the overall susceptibility of pathogens of salivary flora to photodynamic therapy after sensitization with curcumin and exposure to blue light at $450 \mathrm{~nm}$. Methods: A randomized trial was executed with 13 adult volunteers. Three different groups were analyzed: L-D- (no light, no drug; control group), L-D + (treated only with the drug; curcumin group) and L + D+ (treated with drug and light; photodynamic therapy group). Non-stimulated saliva samples were collected for bacterial counts at baseline and after the experimental phase, and adverse events experienced were recorded. Serial dilutions were performed, and the resulting samples were cultured on blood agar plates in microaerophilic conditions. The number of colonyforming units was then determined. Results: There was a considerable difference between the two experimental groups with regard to effectiveness of bacterial reduction. In the L-D+ group, the bacterial decline was considerably smaller $(9 \%)$ than in the $\mathrm{L}+\mathrm{D}+$ group, with a $68 \%$ decrease in bacteria. A statistically significant reduction in the bacterial population was observed only in the photodynamic therapy group $(p<0.05)$. Conclusions: Photodynamic therapy was found to be effective in the reduction of salivary microorganisms. No significant reduction was found for the group in which only curcumin was used, proving the absence of dark toxicity of the drug. This work shows that overall disinfection of the mouth can be done with a simple procedure involving photodynamic action.
\end{abstract}

\section{Introduction}

$\mathbf{T}_{\mathrm{p}}^{\mathrm{h}}$ HE DIVERSITY OF BIOLOGICAL SURFACES in the oral cavity provides many ecological sites for colonization by a variety of oral bacterial species. The mouth is a favorable habitat for $>700$ bacterial species because of the presence of nutrients, epithelial debris, and secretions. ${ }^{1}$ Therefore, the risk of infection is increased in intra-oral surgical procedures, because it is practically impossible to attain aseptic conditions, as a result of the large number of bacteria in the normal mouth. Local postoperative infections are one of the main causes of morbidity in oral surgery. ${ }^{2}$ In some cases, the mouth cavity can even be the main cause of contamination for many types of surgery. Some surgeons advocate the routine use of prophylactic systemic antibiotics to decrease the risk of postoperative infection. However, antibiotics may be associated with unfavorable side effects, ranging from gastrointestinal disturbances to anaphylactic shock and development of resistance. ${ }^{3}$
Another option for decreasing the risk of postoperative infection by temporary reduction of intra-oral bacterial counts is the use of oral antiseptics. Disinfecting solutions, ideally, should be safe to use and effective against pathogens, and should not cause adverse tissue reaction. The most frequently used are chlorhexidine solutions. ${ }^{4}$

Chlorhexidine causes an immediate reduction in the number of salivary bacteria because of its broad activity spectrum. ${ }^{5}$ Its mechanism of action involves interactions with external cell components and the cytoplasmic membrane, causing a high rate of leakage of intracellular components and interactions with cytoplasmic constituents. ${ }^{6}$ Alteration in taste; burning sensation; increase of calculus formation; staining of the teeth and restorative materials; and, more rarely, oral mucosa desquamation and parotid swelling are effects related to its use.

Recently, alternatives that might offer the possibility of efficient intra-oral bacterial count reduction with minimum

\footnotetext{
${ }^{1}$ Dental School of Pernambuco, University of Pernambuco, Camaragibe, PE, Brazil.

${ }^{2}$ Department of Clinical Analysis, School of Pharmaceutical Sciences, University of São Paulo State (UNESP), Araraquara, SP, Brazil.

${ }^{3}$ Institute of Physics of São Carlos, University of São Paulo (USP), São Carlos, SP, Brazil.
} 
damage to systemic health have been sought. In these circumstances, photodynamic therapy (PDT) may offer the possibility of a new approach to oral disinfection.

PDT has been used as a treatment for cancer as well as other nonmalignant diseases. ${ }^{8,9}$ PDT involves the use of a photosensitizer (PS) that is activated by exposure to light of a specific wavelength in the presence of oxygen. The excited PS binds to the target cell and induces the formation of oxygen species, causing localized photodamage and cell death. ${ }^{9-11}$ One advantage of PDT as compared to antibiotics is that bacteria do not develop resistance to oxygen species. As compared to chlorhexidine, PDT does not cause the reported side-effects.

An ideal PS should be nontoxic and should display local toxicity only after activation by illumination. ${ }^{12}$ Curcumin, a compound isolated from Curcuma longa L., has been used for centuries as a medicine, dietary pigment, and spice. The drug possesses a variety of traditional pharmaceutical applications for diseases, including wounds, liver diseases, microbial effects, and inflamed joints. ${ }^{13}$ Curcumin has proved nontoxic in a number of cell culture and whole animal studies. It has a rather broad absorption peak in the range of $300-500 \mathrm{~nm}$ (maximum $\sim 430 \mathrm{~nm}$ ) and exerts potent phototoxic effects in micromolar amounts. Therefore, curcumin has potential as a PS for treatment of localized superficial infections in the mouth or skin. ${ }^{14}$ In addition, this PS has economical advantages considering its low cost, simple manipulation, and great effectiveness.

The effectiveness of PDT against oral bacteria has been the subject of several studies. ${ }^{15-20}$ Zanin et al. ${ }^{18}$ showed the photodynamic activity of some PS on biofilms of Streptococcus mutans, Streptococcus sobrinus, and Streptococcus sanguinis. Zanin et al. ${ }^{20}$ evaluated the phototoxic effect of toluidine blue $\mathrm{O}$ (TBO) on the viability of $S$. mutans biofilms and observed reductions up to $99.99 \%$. Wood et al. ${ }^{17}$ observed the successful photodynamic effects of erythrosine in the killing of $S$. mutans biofilms. Fontana et al. ${ }^{15}$ showed the photodynamic action of methylene blue on human dental plaque microorganisms.

The efficacy of photodynamic action on microorganisms has been extensively investigated using various sensitizers. However, none of those studies used curcumin as a PS for oral decontamination.

In this study, we aim to investigate the effects of PDT on bacteria derived from human saliva. The goal of our research was to detect the susceptibility of pathogens of salivary flora to PDT after sensitization with curcumin and exposure to blue light at $450 \mathrm{~nm}$.

\section{Materials and Methods}

\section{Subjects}

Samples of saliva were taken from 13 healthy subjects aged 25 through 50 years. The study group was composed of 7 female and 6 male participants. The criteria for exclusion from the study were age $<18$ years, pregnancy, using partial or total dentures or orthodontic brackets, presence of systemic diseases, or smoking habit (Fig. 1). None of the subjects had used antibiotics or had undergone medical or dental treatment during the 3 months prior to sampling. The volunteers were not allowed to practice any oral hygiene technique (brushing or flossing) and followed a zero diet (no food)

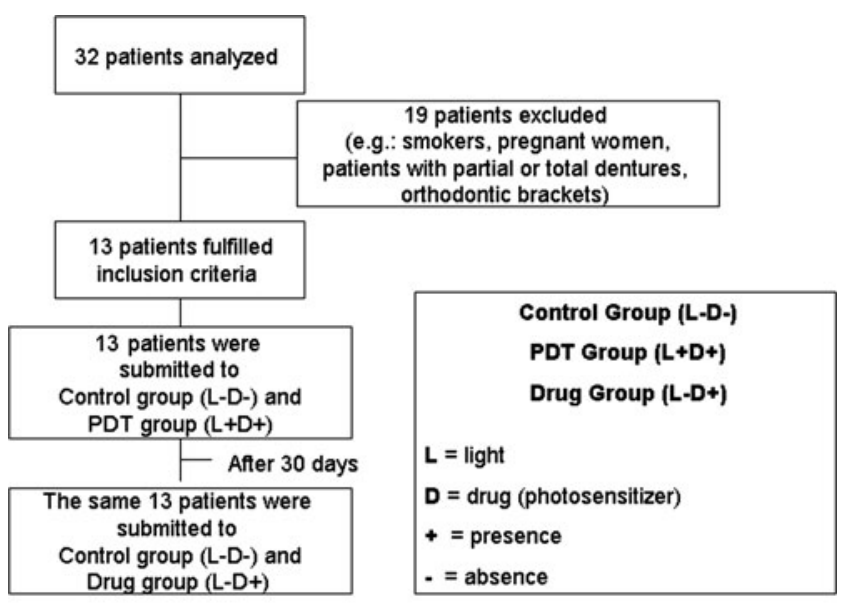

FIG. 1. Selection of patients and tested groups.

during the $12 \mathrm{~h}$ prior to sampling. Permission to collect saliva samples was authorized by the Ethics Committee of the University of Pernambuco (UPE), protocol number 033/11. All subjects also gave their informed consent.

\section{Preparation of blood agar culture plates}

An enriched agar medium was prepared, containing $20 \mathrm{~g} / \mathrm{L}$ of trypticase soy agar (Oxoid Ltd., Basingstoke, Hampshire, England), $26 \mathrm{~g} / \mathrm{L}$ of brain -heart infusion agar (Oxoid Ltd., Basingstoke, Hampshire, England), $10 \mathrm{~g} / \mathrm{L}$ of yeast extract (BBL), and $5 \mathrm{mg} / \mathrm{L}$ of hemin (Sigma Chemical Co., St. Louis, MO). The medium was autoclaved and cooled down to $50^{\circ} \mathrm{C}$. Then, $5 \%$ defibrinated sheep blood (NewProv LTDA, Pinhais PR, Brazil) and $5 \mathrm{mg} / \mathrm{mL}$ of menadione (Sigma Chemical Co., St. Louis, MO) were added under aseptic conditions.

\section{PS}

Curcumin [1,7-bis-(4-hydroxy-3-methoxyphenyl)-1,6-heptadiene-3,5-dione] is an excellent lead compound for drug design and development on the basis of its explicit bioactivities, nontoxicity, and easy synthesis. Curcumin prepared by PDT-Pharma (Cravinhos SP, Brazil) was dissolved in sterile distilled water to give a solution at concentration of $1.5 \mathrm{~g} / \mathrm{L}$ before use.

The ultraviolet-visible absorption spectra of this solution were recorded from 300 to $700 \mathrm{~nm}$ using quartz cuvettes with a 1-cm path length on a Cary 50 Bio UV-Vis spectrometer (Varian, Darmstadt, Germany), and were characterized by a long-wavelength maximum at $430 \mathrm{~nm}$.

\section{Light source}

A blue light-emitting diode (Prototype, Project Finep/ Gnatus LED Edixeon ${ }^{\circledR}$, Edison Opto Corporation, New Taipei City, Taiwan) with an intensity of $67 \mathrm{~mW} / \mathrm{cm}^{2}$, a central wavelength of $450 \mathrm{~nm}$ and an estimated average fluency of $20.1 \mathrm{~J} / \mathrm{cm}^{2}$ was used. The system delivered light by uniform diffusion, which formed a semi-hemispheric illumination within the mouth cavity (Figs. 2 and 3). This spot of light was able to irradiate the full mouth. The power density of 


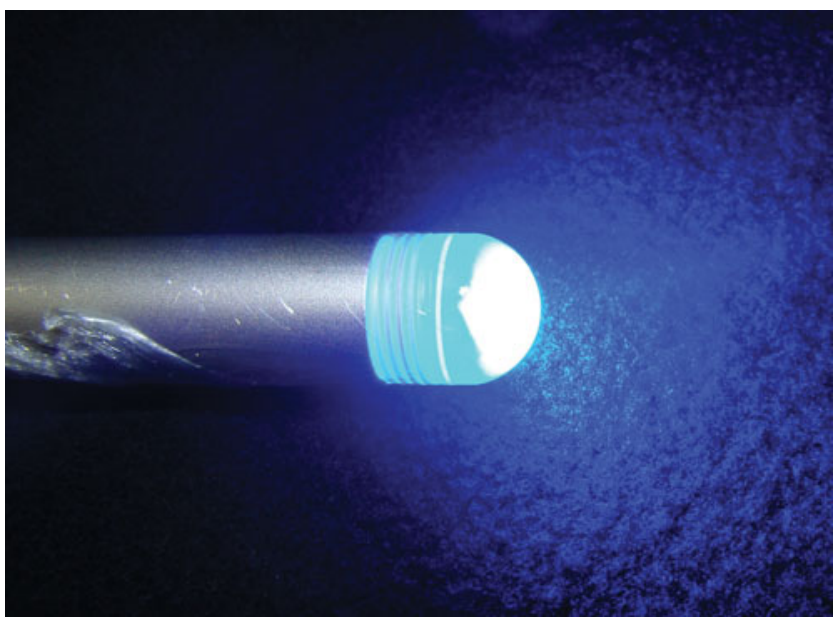

FIG. 2. Blue LED delivering light.

incident radiation was measured using a power meter (Coherent ${ }^{\circledR}$, Santa Clara, CA).

The light parameters used in this study for saliva pathogen reduction were $67 \mathrm{~mW} / \mathrm{cm}^{2}$ (power density) and an estimated average fluency of $20.1 \mathrm{~J} / \mathrm{cm}^{2}$ (energy fluence).

\section{Saliva samples and photodynamic treatment}

Non-stimulated saliva $(2 \mathrm{~mL})$ was collected from each participant using the spitting method at two different periods of time and in three different situations.

Saliva samples for quantitative microbiological analysis at baseline were taken before any oral procedure (L-D-). For the group to which only the drug was administered (L-D+), samples were collected for microbiological analyses after mouth rinse with curcumin; for the group in whom the drug was used in association with light $(\mathrm{L}+\mathrm{D}+)$, samples were collected after PDT (Fig. 1). The group L+D- (only light) was

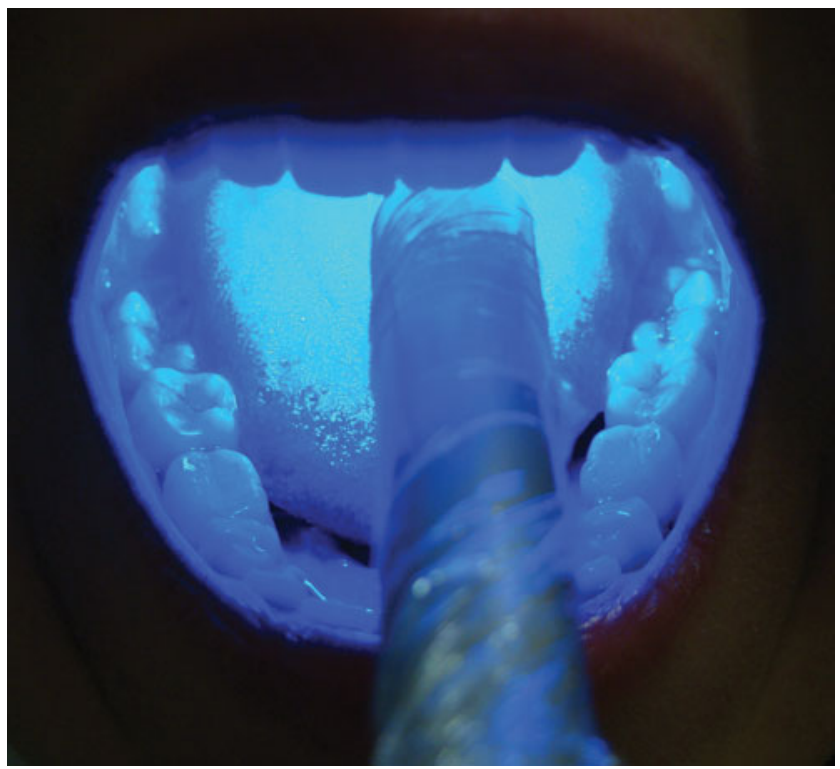

FIG. 3. System delivered light in the mouth cavity. omitted based on previous experience of our group that detected unnoticeable variation with this level of light.

Subjects were instructed to rinse the oral cavity with $20 \mathrm{~mL}$ of curcumin solution $(1.5 \mathrm{~g} / \mathrm{L})$ for $5 \mathrm{~min}$. Then, for the PDT group $(\mathrm{L}+\mathrm{D}+)$, the solution was expelled and a light source was introduced to activate the PS for $5 \mathrm{~min}$. During this period, the temperature did not increase $>1.8^{\circ} \mathrm{C}$.

The saliva samples of the participants, before and after oral cavity washing, with or without PDT, were collected in sterile containers. After illumination of the mouth, saliva samples underwent serial dilutions in brain-heart infusion broth, and 100-microliters aliquots were plated on blood agar plates and then incubated under microaerophilic conditions for $48 \mathrm{~h}$ at $36 \pm 1^{\circ} \mathrm{C}$. After incubation, the total number of colony-forming units (CFU) was determined.

\section{Statistical analysis}

The Statistical Package for Social Sciences (SPSS, Chicago, IL, 2006), version 13.0, was used for processing the data; $p<0.05$ was used as a cutoff level for statistical significance. The data were analyzed for normality of distribution through the use of the Kolmogorov-Smirnov test. The statistical method used for correlating changes in bacterial counts was assessed by Student's $t$ test.

\section{Results}

The action of PDT and curcumin for each subject was determined, verifying the reduction caused in each situation based on the following expression:

$$
\text { Survival Fraction }=\frac{\text { Mean of test group } \cdot(100)}{\text { Mean of control group }}
$$

Survival fractions were evaluated using repeated measures analysis of variance to compare treatment groups. Pairwise comparisons were performed using least significant difference tests.

Figures 4 and 5 and Table 1 show the obtained bacterial reduction for all subjects $(\mathrm{L}-\mathrm{D}+, \mathrm{L}+\mathrm{D}+$ ) and Fig. 6 shows the mean of survival fractions of saliva samples of the study groups. Each value represents the mean survival fraction from triplicate experiments. Whereas for drug alone (L-D+), a reduction of well below $40 \%$ was observed in most

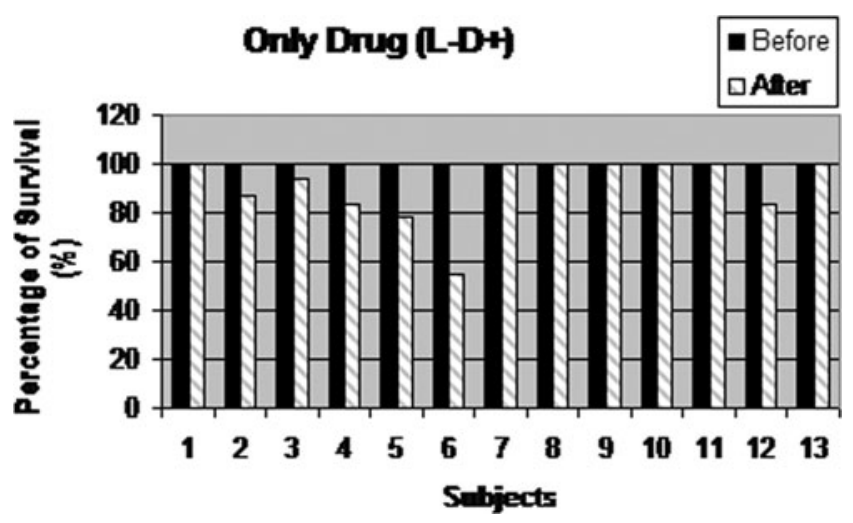

FIG. 4. Bacterial reduction for all subjects after drug mouth rinse $(\mathrm{L}-\mathrm{D}+)$. 


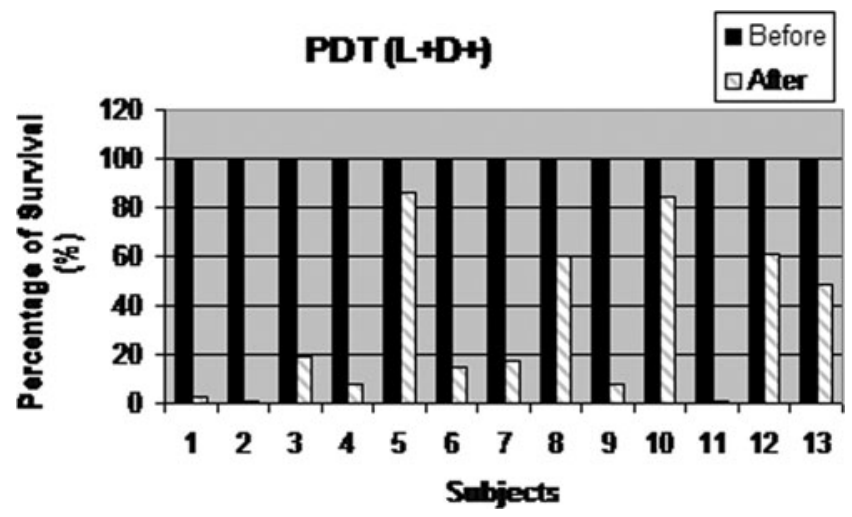

FIG. 5. Bacterial reduction for all subjects after drug mouth rinse followed by blue light $(\mathrm{L}+\mathrm{D}+)$.

individuals (Fig. 4), for the group corresponding to PDT $(\mathrm{L}+\mathrm{D}+)$, a large number of subjects with $90 \%$ reduction was exhibited. In fact, the PDT action caused a reduction of up to 99\% in some subjects (Fig. 5).

In terms of averaging for all subjects (Fig. 6 and Table 1), a $9 \%$ reduction was obtained for the group L-D + , whereas a $68 \%$ reduction was obtained for the group $\mathrm{L}+\mathrm{D}+$. This indicates a significant effect on the reduction of the bacterial quantity in the mouth.

Pairwise comparisons using Student's $t$ test (Table 2) indicated significant differences $(p<0.05)$ between PDT $(\mathrm{L}+\mathrm{D}+)$ and curcumin alone $(\mathrm{L}-\mathrm{D}+)$. The photodynamic therapy group $(\mathrm{L}+\mathrm{D}+)$ produced a statistically significant reduction in salivary bacterial counts in samples taken before PDT and those taken at the end of treatment $(p=0.004)$, whereas the group treated only with drugs showed no influence in bacterial counts $(p=0.052)$.

The synergism of light and curcumin is confirmed in our study: photodynamic therapy killed $68.3 \%$ of bacteria $(p<0.05)$, whereas in the L-D + group with the same volunteers, the effect of the drug alone did not result in an effective reduction of microorganisms.

Table 1. Bacterial Numbers (CFU) of Each Subject at Baseline and After Photodynamic Therapy $(\mathrm{L}+\mathrm{D}+)$ or Mouth Rinse with Curcumin (L-D+)

\begin{tabular}{lllllc}
\hline & \multicolumn{2}{c}{$L+D+$} & & \multicolumn{2}{c}{$L-D+$} \\
\cline { 2 - 3 } \cline { 5 - 5 } Subjects & Before & After & & Before & After \\
\hline 1 & 117 & 3 & 234 & 234 \\
2 & 223 & 1 & 338 & 295 \\
3 & 348 & 68 & 489 & 461 \\
4 & 805 & 61 & 800 & 668 \\
5 & 278 & 241 & 136 & 107 \\
6 & 206 & 30 & 214 & 117 \\
7 & 96 & 17 & 71 & 87 \\
8 & 53 & 32 & 298 & 323 \\
9 & 172 & 14 & 206 & 206 \\
10 & 219 & 185 & 27 & 27 \\
11 & 283 & 4 & 800 & 800 \\
12 & 354 & 216 & 800 & 668 \\
13 & 238 & 116 & 800 & 800 \\
Mean & 260.79 & 75.85 & 400.92 & 368.46 \\
\hline
\end{tabular}

\section{Discussion}

The preoperative use of antiseptics in oral surgery is controversial. Many studies confirm that they reduce intraoral bacteria and decrease bacteremia during surgical procedures. ${ }^{4,21-23}$ However, most surgeons are not convinced of their effect on reduction of postoperative infections. ${ }^{24}$

There is no generally accepted universal protocol for preoperative antimicrobial prophylaxis in oral surgery, but chlorhexidine gluconate is the most frequently used antiseptic solution and the most effective compound that shows pronounced antimicrobial effects both on Gram-positive and Gram-negative bacteria, as well as on fungi and some viruses. ${ }^{5,25}$ However, it has not been recommended for use over long intervals because of the related side effects. ${ }^{7,26}$

Therefore, the study of new technologies for use in association with mouth rinse is very important. The technique of PDT may offer several advantages compared to traditional antimicrobial mouth rinses.

First, bacterial killing is fast, reducing the necessity for high concentrations of chemical substance. Second, as the death of the bacteria is linked to the mediation of reactive species, the development of bacterial resistance is unlikely. As demonstrated in our study, the PS by itself is not bactericidal, and bacterial reduction can be controlled by restricting the irradiated area. ${ }^{27-30}$

Therefore, PDT may be an interesting alternative to antibiotics and antiseptics used for oral bacteria reduction. Several studies have demonstrated the susceptibility of oral bacteria to PDT, ${ }^{15-20}$ but despite studies that have shown the effectiveness of this procedure, some factors can influence the success of this treatment, such as type, concentration, and incubation time of the sensitizers; the microorganism species; the light source; and the given dose.

Most studies evaluating the efficacy of PDT on oral bacteria used TBO and methylene blue as PS, followed by irradiation with a red LED light. ${ }^{11,31-35}$ Williams et al. ${ }^{31}$ noted $100 \%$ death of $S$. mutans in a planktonic suspension, using an LED with TBO as the PS. Neither TBO dye nor light alone had a significant antibacterial effect under the experimental conditions used. These results and our findings highlight the need for dye-light conjugation to ensure the effectiveness of PDT. The photodynamic effects of the binomial dye-light were also confirmed by Giusti et al. ${ }^{35}$ Photogem and TBO activated by red light caused bacterial reduction of Lactobacillus acidophilus and S.mutans in carious dentin.

The TBO dye is a common substance used in $\mathrm{PDT}^{36}$; however, its use in the mouth can change the color of tooth surfaces and restorations of resin-based composite. ${ }^{35}$ In this article, a blue LED $(450 \mathrm{~nm})$ with an intensity of $67 \mathrm{~mW} / \mathrm{cm}^{2}$ was used together with a curcumin solution with a concentration of $1.5 \mathrm{~g} / \mathrm{L}$. The dyes work as optical absorption agents and are activated by irradiation with light of a specific wavelength, resulting in the generation of cytotoxic species, including singlet oxygen and free radicals, that exert a bactericidal effect but that are not toxic to host cells., 90

As there is no published work, to our best knowledge, reporting the use of curcumin as a mouth rinse followed by illumination to promote oral cavity decontamination, it was our aim to perform a pilot study. Although this study has been conducted with only 13 patients, our intention was to show that the procedure using mouthwash is safe and that 


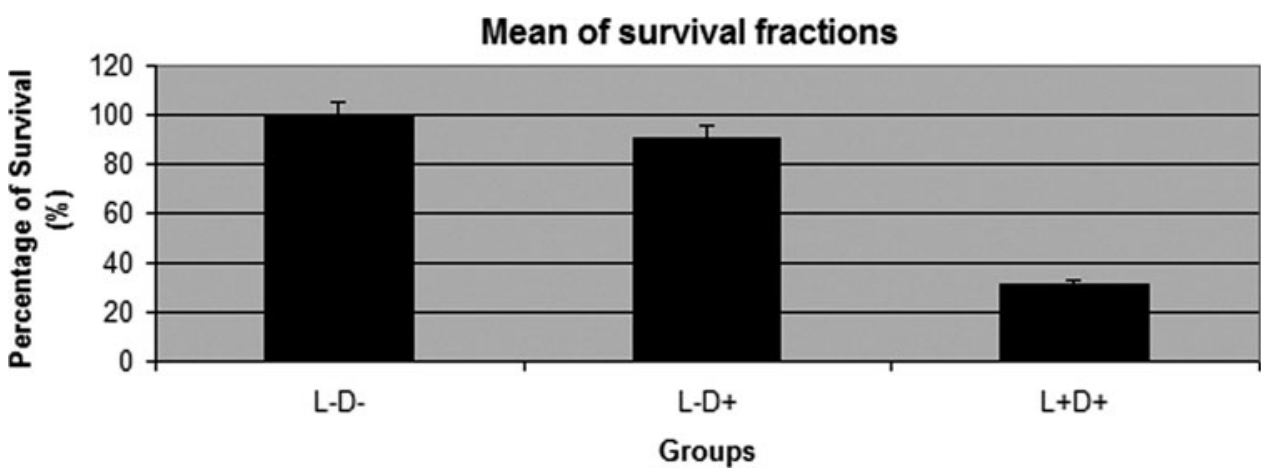

FIG. 6. Mean of microorganisms survival of studied groups - Same letter (A) means no significant difference $(p>0.05)$.

there is no dark toxicity effect. In this pilot study, the effective bacterial reduction provided by the photodynamic effect was significantly higher than that provided by other groups. These results are quite significant, encouraging us to perform more specific studies involving clinical periodontal parameters (i.e., pocket depth, bleeding on probing, and attachment level) with more patients and long-term observations.

Curcumin is shown to be a PS that is attached to the bacterial walls, drawing to itself the light at the time of irradiation with an essential antimicrobial action on oral bacteria. The concentration of curcumin was chosen based on another study that determined a safe concentration in terms of damage to the mucosa and of discoloration of the teeth. ${ }^{37}$ The concentration of $1.5 \mathrm{~g} / \mathrm{L}$ is in fact a very low concentration; even at such concentration, the results were surprisingly good. A reduction of $>65 \%$ of microorganisms contained in saliva using a simple procedure is quite encouraging for a further development of the technique. The reduction is comparable to the results for rinsing with traditional oral solutions containing chlorhexidine and alcohol. ${ }^{23}$ The great advantage to using curcumin is that it is a natural substance and harmless to the oral tissues. ${ }^{14}$

Neither a burning sensation, nor oral soreness, nor aphthous ulcers were reported by any subjects; however, oral itching was reported by a few volunteers. There was no significant difference for occurrence of adverse events between the two experimental groups ( $\mathrm{L}-\mathrm{D}+$ and $\mathrm{L}+\mathrm{D}+$ ).

Overall, decontamination using this simple procedure is a desirable technique for general use in everyday dentistry practice. It should allow great improvement in avoiding complications during oral surgical procedures.

An important aspect of our demonstration is the very low price of curcumin (US $\$ 5 /$ micrograms), making possible the

Table 2. Mean of Bacterial Numbers (CFU) at Baseline and After Performing Photodynamic Therapy $(\mathrm{L}+\mathrm{D}+)$ Or a Mouth Rinse with Curcumin (L-D+)

\begin{tabular}{lccc}
\hline & Mean baseline & Mean after & p Value \\
\hline $\mathrm{L}+\mathrm{D}+$ & $260.79^{\mathrm{a}}$ & $75.85^{\mathrm{b}}$ & 0.004 \\
$\mathrm{~L}-\mathrm{D}+$ & $400.92^{\mathrm{a}}$ & $368.46^{\mathrm{a}}$ & 0.052 \\
\hline
\end{tabular}

${ }^{a} t$ tests between groups (2-sided).

In rows, means with the same letter are not significantly different $(p>0.05)$. production of a PS at affordable prices. That is an important requirement for making a PDT-type procedure a reality.

\section{Conclusions}

In conclusion, in this study, the results indicate that PDT is a promising alternative for reducing the risk of postoperative infection by temporary reduction of intra-oral bacterial counts.

\section{Acknowledgment}

The authors thank all the volunteers who participated in this study. Financial support from Research Support Foundation of São Paulo State (FAPESP), Studies and Projects Financier (FINEP), Science and Technology Support Foundation of Pernambuco State (FACEPE), and Medical and Dental Equipment Gnatus was appreciated.

\section{Author Disclosure Statement}

No competing financial interests exist.

\section{References}

1. Polgárová, K., Behuliak, M., and Celec, P. (2010). Effect of saliva processing on bacterial DNA extraction. New Microbiol. 33, 373-379.

2. Summers, A.N., Larson, M.D., Edmiston, C.E., Gosain, A.K., Denny, A.D., and Radke, L. (2000). Efficacy of preoperative decontamination of the oral cavity. Plast. Reconstr. Surg. 106, 895-900.

3. Dar-Odeh, N.S., Abu-Hammad, O.A., Al-Omiri, M.K., Khraisat, A.S., and Shehabi, A.A. (2010). Antibiotic prescribing practices by dentists: a review. Ther. Clin. Risk Manag. 21, 301-306.

4. Pitten, F.A., and Kramer, A. (1999). Antimicrobial efficacy of antiseptic mouthrinse solutions. Eur. J. Clin. Pharmacol. 55, 95-100.

5. Gilbert, P., and Moore, L.E. (2005). Cationic antiseptics: diversity of action under a common epithet. J. Appl. Microbiol. 99, 703-715.

6. Maillard, J.Y. (2002). Bacterial target sites for biocide action. J. Appl. Microbiol. 92, Suppl., 16S-27S.

7. Arweiler, N.B., Auschill, T.M., Reich, E., and Netuschil, L. (2002). Substantivity of toothpaste slurries and their effects on reestablishment of the dental biofilm. J. Clin. Periodontol. 29, 615-621.

8. Huang, Z. (2005). A review of progress in clinical photodynamic therapy. Technol. Cancer Res. Treat. 4, 283-293. 
9. Al-Watban, F.A., and Zhang, X.Y. (2005). Photodynamic therapy of human undifferentiated thyroid carcinoma-bearing nude mice using topical 5-aminolevulinic acid. Photomed. Laser Surg. 23, 206-211.

10. Komerik, N., and Wilson, M. (2002). Factors influencing the susceptibility of Gram-negative bacteria to toluidine blue Omediated lethal photosensitization. J. Appl. Microbiol. 92, 618-623.

11. O'neill, J.F., Hope, C.K., and Wilson, M. (2002). Oral bacteria in multi-species biofilms can be killed by red light in the presence of toluidine blue. Lasers Surg. Med. 31, 86-90.

12. Meisel, P., and Kocher, T. (2005). Photodynamic therapy for periodontal diseases: state of the art. J. Photochem. Photobiol. B. 79, 159-170.

13. Aggarwal, B.B., Sundaram, C., Malani, N., and Ichikawa, H. (2007). Curcumin: the Indian solid gold. Adv. Exp. Med. Biol. 595, 1-75.

14. Haukvik, T., Bruzell, E., Kristensen, S., and Tønnesen, H.H. (2010). Photokilling of bacteria by curcumin in selected polyethylene glycol 400 (PEG 400) preparations. Studies on curcumin and curcuminoids, XLI. Pharmazie 65, 600-606.

15. Fontana, C.R., Abernethy, A.D., Som, S., et al. (2009). The antibacterial effect of photodynamic therapy in dental plaque-derived biofilms. J. Periodontal Res. 44, 751-759.

16. Metcalf, D., Robinson, C., Devine, D., and Wood, S. (2006). Enhancement of erythrosine-mediated photodynamic therapy of Streptococcus mutans biofilms by light fractionation. J. Antimicrob. Chemother. 58, 190-192.

17. Wood, S., Metcalf, D., Devine, D., and Robinson, C. (2006). Erythrosine is a potential photosensitizer for the photodynamic therapy of oral plaque biofilms. J. Antimicrob. Chemother. 57, 680-684.

18. Zanin, I. C., Lobo, M.M., Rodrigues, L.K., Pimenta, L.A., Höfling, J.F., and Gonçalves, R.B. (2006). Photosensitization of in vitro biofilms by toluidine blue $\mathrm{O}$ combined with a light-emitting diode. Eur. J. Oral Sci. 114, 64-69.

19. Komerik, N., and MacRobert, A.J. (2006). Photodynamic therapy as an alternative antimicrobial modality for oral infections. J. Environ. Pathol. Toxicol. Oncol. 25, 487-504.

20. Zanin, I. C., Gonçalves, R.B., Junior, A.B., Hope, C.K., and Pratten, J. (2005). Susceptibility of Streptococcus mutans biofilms to photodynamic therapy: an in vitro study. J. Antimicrob. Chemother. 56, 324-330.

21. Netuschil, L., Weiger, R., Preisler, R., and Brecx, M. (1995). Plaque bacteria counts and vitality during chlorhexidine, meridol and listerine mouthrinses. Eur. J. Oral Sci. 103, 355-361.

22. Tomás, I., Cousido, M.C., Tomás, M., Limeres, J., GarcíaCaballero, L., and Diz, P. (2008). In vivo bactericidal effect of $0.2 \%$ chlorhexidine but not $0.12 \%$ on salivary obligate anaerobes. Arch. Oral Biol. 53, 1186-1191.

23. Herrera, D., Roldan, S., Santacruz, I., Santos, S., Masdevall, M., and Sanz, M. (2003). Differences in antimicrobial activity of four commercial $0.12 \%$ chlorhexidine mouthrinse formulations: an in vitro contact test and salivary bacterial counts study. J. Clin. Periodontol. 30, 307-314.
24. Heit, J.M., Farhood, V.W., and Edwards, R.C. (1991). Survey on antibiotic prophylaxis for intraoral orthognathic surgery. J. Oral Maxillofac. Surg. 49, 340-342.

25. McDonnell, G., and Russell, A.D. (1999). Antiseptics and disinfectants: activity, action, and resistance. Clin. Microbiol. Rev. 12, 147-179.

26. Owens, J., Addy, M., Faulkner, J., Lockwood, C., and Adair, R. (1997). A short-term clinical study design to investigate the chemical plaque inhibitory properties of mouthrinses when used as adjuncts to toothpastes applied to chlorhexidine. J. Clin. Periodontol. 24, 732-737.

27. Tamietti, B.F., Machado, A.H., Maftoum-Costa, M., Da Silva, N.S., Tedesco, A.C., and Pacheco-Soares, C. (2007). Analysis of mitochondrial activity related to cell death after PDT with AlPCS(4). Photomed. Laser Surg. 25, 175-179.

28. Burns, T., Wilson, M., and Pearson, G.J. (1995). Effect of dentine and collagen on the lethal photosensitization of Streptococcus mutans. Caries Res. 29, 192-197.

29. Wilson, M., and Dobson, J. (1993). Lethal photosensitization of oral anaerobic bacteria. Clin. Infect. Dis. 16, S414-S415.

30. Wilson, M., Tracy, B., and Pratten, J. (1996). Killing of Streptococcus sanguis in biofilms using a light-activated antimicrobial agent. J. Antimicrob. Chemother. 37, 377-381.

31. Williams, J.A., Pearson G.J., Colles, M.J., and Wilson, M. (2003). The effect of variable energy input from a novel light source on the photoactivated bactericidal action of toluidine blue O on Streptococcus Mutans. Caries Res. 37, 190-193.

32. Wilson, M., Dobson, J., and Harvey, W. (1992). Sensitization of oral bacteria to killing by low-power laser radiation. Curr. Microbiol. 25, 77-81.

33. Wilson, M., Burns, T., and Pratten, J. (1996). Killing of Streptococcus sanguis in biofilms using a lightactivated antimicrobial agent. J. Antimicrob. Chemother. 37, 377-381.

34. Wilson, M., Burns, T., Pratten, J., and Pearson, G.J. (1995). Bacteria in supragingival plaque samples can be killed by low-power laser light in the presence of a photosensitizer. J. Appl. Bacteriol. 78, 569-574.

35. Giusti, J.S., Santos-Pinto, L., Pizzolito, A.C., et al. (2008). Antimicrobial photodynamic action on dentin using a lightemitting diode light source. Photomed. Laser Surg. 26, 281-287.

36. Usacheva, M.N., Teichert, M.C., and Biel, M.A. (2001). Comparison of the methylene blue and toluidine blue photobactericidal efficacy against gram-positive and gramnegative microorganisms. Lasers Surg. Med. 29, 165-173.

37. Sharma, R.A., Gescher, A.J., and Steward, W.P. (2005). Curcumin: the story so far. Eur. J. Cancer 41, 1955-1968.

Address correspondence to: Natália Costa Araújo 57 Dom Sebastião Leme Street Recife, $P E$

Brazil 52011-160

E-mail: nataliacosta84@yahoo.com.br 